\title{
Relationship between disaster prevention awareness and preparedness among residents living in mountainous areas of Japan
}

\author{
Miyuki TADA ${ }^{1}$, Saori IWAMOTO ${ }^{2}$, Hiroki $\mathrm{KUBO}^{3}$ and Ayano SENOU 4 \\ ${ }^{1}$ Department of Community Health Nursing, Graduate School of Biomedical Sciences, Tokushima University, Tokushima, Japan \\ ${ }^{2}$ Department of Public Health Nursing, Kobe City College of Nursing, Kobe, Japan \\ ${ }^{3}$ Naruto City Health and Welfare Department Health Promotion Division, Tokushima, Japan \\ ${ }^{4}$ Yoshinogawa City Health and Welfare Department Health Promotion Division, Tokushima, Japan
}

\begin{abstract}
Aim: This study aimed to clarify the factors influencing disaster prevention awareness and their association with disaster preparedness among residents living in mountainous areas of Japan.

Methods: An anonymous self-administered questionnaire survey was conducted with health examination participants in City A in August 2018. The survey items included basic attributes, disaster prevention awareness and related factors, and disaster preparedness. Descriptive statistics were performed on each item, followed by a $t$-test and multiple regression analysis.

Results: In total, 113 (48.7\%) valid responses were received. The mean total score on the Disaster Prevention Awareness Scale was 82.3, which was significantly higher than that found in a national survey $(p<0.01)$. As a result of the multiple regression analysis, "Number of years of residence" and "Experience participating in disaster prevention events" were extracted as factors affecting disaster awareness $\left(R^{2}=0.222\right)$. Significant relationships $(p<0.05)$ were found for all sub-factors except "Be covered by earthquake insurance".

Conclusion: The implementation rate of disaster prevention awareness and preparedness among residents living in mountainous areas of Japan was higher than that reported in a national survey. "Number of years of residence" and "Experience participating in disaster prevention events" were extracted as factors affecting disaster awareness. In the context of preparedness, all items were related, except for "Be covered by earthquake insurance", which is difficult to address, even if disaster prevention awareness is high, because it represents an economic burden.
\end{abstract}

Key words: disaster preparedness, disaster prevention awareness, Japan, mountainous areas, multiple regression analysis

Correspondence: Miyuki Tada, Department of Community Health Nursing, Graduate School of Biomedical Sciences, Tokushima University, 3-18-15 Kuramoto-cho, Tokushima 770-8509, Japan. Email: tada.miyuki@tokushima-u.ac.jp

Received 30 October 2020; accepted 25 May 2021; J-STAGE advance published 12 August 2021.

(c) (i) This article is licensed under a Creative Commons Attribution 4.0 International license.

\section{INTRODUCTION}

Approximately $20 \%$ of earthquakes having a magnitude of 6.0 around the world occur in Japan, which only has $0.25 \%$ of the world's land area (Cabinet Office, 2010). In 2018, the consecutive occurrence of disasters across Japan, including earthquakes, heavy rains, and typhoons, caused extensive damage in many regions, which indicated the necessity of creating a disaster prevention awareness society with awareness of the "self-protection of life" (Cabinet Office, 2019a). 
In a survey on disaster prevention conducted by the Japanese Government in September 2002, 34.9\% of the respondents reported that they had previously discussed the occurrence of a disaster with their close friends or family members (Cabinet Office, 2002), compared with $57.7 \%$ in a survey conducted in November 2017 (Cabinet Office, 2017). This apparently growing increase in disaster prevention may be due to the impact of the Great East Japan Earthquake of 2011, accompanied by awareness of a large earthquake expected to occur in the near future (the Nankai Trough Mega Earthquake).

Against this backdrop, disaster preparedness is an urgent issue, and the need to raise awareness of reducing disaster risk among residents has been pointed out in a wide range of areas, including as part of the national Basic Disaster Reduction Plans (Cabinet Office, 2019b). Previous studies on disaster prevention awareness among local residents have included research on the structures of disaster prevention awareness (Ishihara \& Matsumura, 2012) and awareness of natural disasters and factors related to disaster prevention behaviors (Gisela, Ortwin, Chloe, \& Christian, 2013; Reininger et al., 2013). However, only a few of these previous studies have used subjective indicators, such as those that developed questions about disaster prevention awareness independently, those that asked about disaster prevention behaviors, and those that used objective indicators to measure disaster prevention awareness.

At the time of the Great East Japan Earthquake, severe damage was caused by not only the earthquake, but also the resultant tsunami; therefore, inhabitants living in coastal areas and in each municipality are highly aware of the dangers associated with a tsunami (Takahashi \& Masaki, 2012; Arias, Bronfman, Cisternas, \& Repetto, 2017). As a result, measures such as the development of a tsunami hazard map are being undertaken (Ministry of Land, Infrastructure and Transport (MLIT), 2011; Koshimura \& Shuto, 2015). In contrast, mountainous areas are associated with a lower risk of tsunami damage, so residents living in these areas may have insufficient disaster awareness and preparedness compared with those living in coastal areas.

Therefore, this study aimed to conduct an objective evaluation of disaster prevention awareness among residents living in City A using the Disaster Prevention Awareness Scale devised by Shimazaki and Ozeki (2017), and to clarify the factors influencing disaster prevention awareness and their association with disaster preparedness.

\section{DEFINITION OF TERMS}

\section{Disaster prevention awareness}

In this study, "disaster prevention awareness" refers to the degree to which an individual is routinely aware that a disaster can occur and that information, materials, or social preparedness is needed, as well as the degree to which they attempt to protect themselves, the life or property of others, the local community, and the culture of the region (Ozeki, Shimazaki, \& Yi, 2017).

\section{Disaster preparedness}

"Disaster preparedness" refers to the actions taken at all times to minimize damage, enhance safety, and protect lives in the event of natural disasters such as earthquakes (Fujimura, Ishii, Sakaguchi, Murakawa, \& Akihara, 2013).

\section{OUTLINE OF CITY A}

City A is located in a mountainous area in the interior of the prefecture, with a forested area of $\geq 85 \%$. As of January 1, 2019, City A had a population of 24,717 with an aged population ( $\geq 65$ years) of more than $40 \%$. A central structural line tomographic zone, one of the most active tomography zones in Japan, runs east and west of the central urban area of the city, and thus, the potential occurrence of the Nankai Trough Giant Earthquake in City A is a concern. Regarding the damage expected to be caused by the Nankai Trough Mega Earthquake, the danger of a tsunami and liquefaction is low, and most areas are expecting to experience a magnitude of $\leq 6$. City A has also been affected by soil and sand decay because of the effects of heavy rains that occurred in July 2018.

\section{METHODS}

\section{Data collection method}

An anonymous self-administered questionnaire survey was conducted on lay health examination participants in City A in August 2018. The researchers distributed questionnaires that were collected in a collection box at a medical examination venue.

\section{Study content}

\section{Basic attributes}

We asked the participants about characteristics such as age, sex, occupation, number of years of residence, household structure, and perceived subjective health. 


\section{Disaster prevention awareness}

The Disaster Prevention Awareness Scale prepared by Shimazaki and Ozeki (2017) was used with permission from the authors. This scale is composed of 20 items and the following five subscales: (1) imagination about the disaster situation; (2) sense of crisis about disasters; (3) orientation toward others; (4) interest in disasters; and (E) anxiety. The respondents are asked to rate these items on a six-point Likert-type scale, from 1, "Not true at all," to 6 , "Very true." Thus, the score on the scale ranges from 20 to 120 points.

\section{Factors related to disaster prevention awareness}

Referring to previous studies, the authors asked about each participant's experiences (as well as people close to them) with major disasters, conversations about disaster prevention on a daily basis, and experience participating in disaster prevention events.

\section{Disaster preparedness}

Based on a survey conducted by the Cabinet Office (2016), "Actions to be taken in preparation for a disaster" questionnaires were developed to help prepare for 10 types of disasters (described below). The questions asked whether such preparations should be implemented.

\section{Analytical methods}

Basic statistics were calculated for all survey items. To compare disaster prevention awareness in City A with the results of a nationwide survey, a $t$-test was carried out on the Disaster Prevention Awareness Scale total and subfactor scores. Then, multiple regression analysis was conducted to examine the factors affecting disaster awareness, with basic attributes and factors related to disaster awareness as independent variables and the total score on the Disaster Prevention Awareness Scale as a dependent variable. The variance inflation factor was calculated to account for the effect of multiple collinearity. In the analysis, occupation was divided into employed, which included regular and part-time staff, farmer, self-employed, housewife, and unemployed. Household structure was categorized as single household, nuclear family (couples only), two generations, or three generations or more (extended family members). Perception of subjective health was categorized as very healthy, somewhat healthy, somewhat unhealthy, and very unhealthy. In addition, to examine the relationship with disaster preparedness, an integrated $t$-test was performed on the results from the Disaster Prevention Awareness Scale. All statistical analyses were carried out using SPSS Statistics version 22 (SPSS Inc., Chicago, IL, USA), with a significance level of $5 \%$.

\section{Ethical considerations}

This study was approved by the Ethics Committee of the Clinical Research Ethics Review Board of Tokushima University Hospital (approval No. 2935). The study purpose and methods were explained to the relevant persons working in the health promotion division of City A before the medical examinations were carried out, and consent was obtained from all workers. Explanatory documents and survey forms were then distributed to the participants, along with written explanations of the study purpose and methods. All participants indicated their consent to participate by checking a consent column on the survey form. All participants received an explanation that their consent was voluntary and that there would be no repercussions from choosing not to participate in the study.

\section{RESULTS}

Of the 232 individuals who received a questionnaire, responses were received from 152 (response rate: 65.5\%), of which 113 were considered valid (valid response rate: 48.7\%). The criterion for validity was to answer all the questions on the Disaster Prevention Awareness Scale.

\section{Participant characteristics}

The mean age ( \pm standard deviation $[\mathrm{SD}]$ ) of the participants (54 [47.8\%] males and 59 [52.2\%] females) was $62.5( \pm 15.3)$ years. The number of unemployed people was the highest, at $51(45.1 \%)$. The mean $( \pm \mathrm{SD})$ number of years of residence in City A was $45.2( \pm 21.9)$, the most prevalent household type was "couples only" (53 $[46.9 \%]$ ), and the most prevalent perception of subjective health was "somewhat healthy" (93 [82.3\%]; Table 1).

\section{Actual situation of disaster prevention awareness}

The mean $( \pm$ SD) total score on the Disaster Prevention Awareness Scale was $82.3( \pm 11.5)$ out of 120 points, with the highest and lowest scores being 110 and 55 points, respectively. The mean $( \pm \mathrm{SD})$ sub-factor scores were $14.3( \pm 4.3)$ points for "(1) imagination about the disaster situation", $20.1( \pm 3.4)$ for "(2) sense of crisis about disasters", $16.6( \pm 4.1)$ for "(3) orientation toward others", $15.9( \pm 3.1)$ for "(4) interest in disasters", and 15.5 ( \pm 3.9$)$ for "(5) anxiety". When compared with the results of the national survey by Shimasaki and Ozeki (2017), both the total and sub-factor scores were significantly higher on the Disaster Prevention Awareness Scale $(p<0.01$; Fig. 1 , Table 2). 
Table 1 Characteristics of the participants $(n=113)$

\begin{tabular}{|c|c|c|}
\hline Variable & Category & $\begin{array}{l}\text { Overall means } \\
\pm \text { SDs or } n(\%)\end{array}$ \\
\hline \multirow[t]{8}{*}{ Age (years) } & & $62.5 \pm 15.3$ \\
\hline & $20-29$ & $6(5.3)$ \\
\hline & $30-39$ & $7(6.2)$ \\
\hline & $40-49$ & $6(5.3)$ \\
\hline & $50-59$ & $12(10.6)$ \\
\hline & $60-69$ & $45(39.8)$ \\
\hline & $70-79$ & $27(23.9)$ \\
\hline & $80-89$ & $10(8.8)$ \\
\hline \multirow[t]{2}{*}{ Sex } & Male & $54(47.8)$ \\
\hline & Female & $59(52.2)$ \\
\hline \multirow{5}{*}{$\begin{array}{l}\text { Employment } \\
\text { status }\end{array}$} & Full-time & $3(2.7)$ \\
\hline & Part-time & $9(8.0)$ \\
\hline & Agriculture and self-employed & $20(17.7)$ \\
\hline & Housewife & $30(26.5)$ \\
\hline & Unemployed & $51(45.1)$ \\
\hline \multirow{10}{*}{$\begin{array}{l}\text { Number of years } \\
\text { of residence }\end{array}$} & & $45.2 \pm 21.9$ \\
\hline & $<10$ & $9(8.0)$ \\
\hline & $10-19$ & $10(8.8)$ \\
\hline & $20-29$ & $5(4.4)$ \\
\hline & $30-39$ & $11(9.7)$ \\
\hline & $40-49$ & $25(22.1)$ \\
\hline & $50-59$ & $16(14.2)$ \\
\hline & $60-69$ & $21(18.6)$ \\
\hline & $70-79$ & $13(11.5)$ \\
\hline & $80-89$ & $3(2.7)$ \\
\hline \multirow{4}{*}{$\begin{array}{l}\text { Household } \\
\text { structure }\end{array}$} & Single & $8(7.1)$ \\
\hline & Couple only & $53(46.9)$ \\
\hline & Two generations & $39(34.5)$ \\
\hline & Three generations or more & $13(11.5)$ \\
\hline \multirow[t]{4}{*}{ Subjective health } & Very healthy & $9(8.0)$ \\
\hline & Somewhat healthy & $93(82.3)$ \\
\hline & Somewhat unhealthy & $10(8.8)$ \\
\hline & Very unhealthy & $1(0.9)$ \\
\hline
\end{tabular}

$\mathrm{SD}$, standard deviation.

\section{Factors affecting disaster prevention awareness}

Age was excluded because of the presence of multiple collinearity in age and number of years of residence. The coefficient of determination $\left(\mathrm{R}^{2}\right)$ of the regression equation was 0.222 , and "Number of years of residence" and "Experience participating in disaster prevention events" were extracted as influencing factors. The standardized coefficients $(\beta)$ for "Number of years of residence" and "Experience participating in disaster prevention events" were $0.255(p=0.011)$ and 0.198 $(p=0.030)$, respectively (Table 3$)$.

\section{Association between disaster prevention aware- ness and preparedness}

Regarding disaster preparedness, the most common factor reported by the participants was "Ensure that mobile radios, flashlights, and pharmaceuticals can be accessed immediately" (76 [67.3\%]), followed by "Identify evacuation sites and routes in the event of a disaster" (74 [65.5\%]) and "Store food and drinking water" (70 [61.9\%]).

Those who were carrying out disaster preparedness had significantly higher total scores for all items on the Disaster Prevention Awareness Scale, except for "Be covered by earthquake insurance" compared with those who were not $(p<0.05$; Table 4$)$.

\section{DISCUSSION}

\section{Disaster prevention awareness and preparedness among residents of mountainous areas}

Regarding disaster prevention awareness, in this study, the mean total score on the Disaster Prevention Awareness Scale for City A was 82.3 points, which was significantly higher than that for the national survey of adult men and women reported by Shimazaki and Ozeki (2017). Particularly in City A, the score for "(3) orientation toward others" was high among the five sub-factors; this sub-factor refers to the intention to do something for the benefit of others and society (National Research Institute for Earth Science and Disaster Resilience (NIED), 2017). During a disaster, helping not only oneself, but also others in the surrounding area, is important, and the residents of City A were therefore considered to have a high level of awareness in this regard. Similarly, the implementation rate for disaster preparedness in City A was higher for all items on the Disaster Prevention Awareness Scale compared with the results of the national survey (Cabinet Office, 2019b). The top three items were the same, but the implementation rates were over $20 \%$ higher. This result may be attributed, in part, to the fact that in City A, many disasters, such as snow damage and landslides, have occurred in the past, and in July 2018, heavy rains caused extensive damage, including landslides (MLIT, 2019), which led to improved disaster prevention awareness and preparedness among the residents. However, although the implementation rate of each item was higher compared with the results of the national survey, the implementation rates of the items "Talking about helping the neighborhood and friends in the event of a disaster", "Deciding how to check the family's safety in the event of a disaster" and "Preparing clothing and blankets for an 


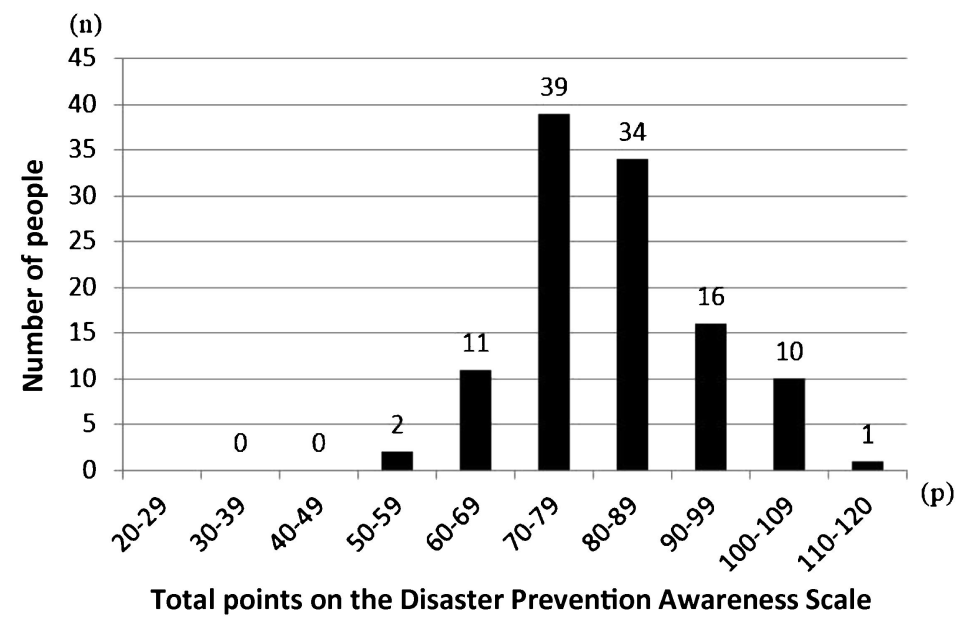

Figure 1 Distribution of total points on the Disaster Prevention Awareness Scale.

Table 2 Comparison of scores on the Disaster Prevention Awareness Scale with a national survey $(\mathrm{n}=113)$

\begin{tabular}{|c|c|c|c|c|}
\hline Variable & Category & Mean & $\mathrm{SD}$ & $t$-test; $p$ value \\
\hline \multirow{2}{*}{ Overall score } & City A & 82.3 & 11.5 & \multirow{2}{*}{$0.000^{*}$} \\
\hline & Nationwide & 73.3 & 9.3 & \\
\hline \multirow{2}{*}{ A: Imagination about the disaster situation } & City A & 14.3 & 4.3 & \multirow{2}{*}{$0.003^{*}$} \\
\hline & Nationwide & 13.0 & 3.3 & \\
\hline \multirow{2}{*}{ B: Sense of crisis about disasters } & City A & 20.1 & 3.4 & \multirow{2}{*}{$0.000^{*}$} \\
\hline & Nationwide & 17.7 & 3.3 & \\
\hline \multirow{2}{*}{ C: Orientation toward others } & City A & 16.6 & 4.1 & \multirow{2}{*}{$0.000^{*}$} \\
\hline & Nationwide & 13.2 & 3.5 & \\
\hline \multirow{2}{*}{ D: Interest in disasters } & City A & 15.9 & 3.1 & \multirow{2}{*}{$0.001^{*}$} \\
\hline & Nationwide & 14.8 & 3.3 & \\
\hline \multirow{2}{*}{ E: Anxiety } & City A & 15.5 & 3.9 & \multirow{2}{*}{$0.000^{*}$} \\
\hline & Nationwide & 13.4 & 2.6 & \\
\hline
\end{tabular}

$\mathrm{SD}$, standard deviation.

${ }^{*} p<0.01$.

emergency" were only $\sim 30 \%$. This is probably due to the high awareness of mutual assistance, which is taken for granted on a daily basis, and that residents dare not talk about it in terms of a "disaster." It is considered probable that the residents did not feel the necessity to implement these items because they are supposed to be able to assist each other with emergency goods. In addition, although the utilization of the voice message board "NTT Disaster Emergency Message Dial 171" is generally recommended in the event of a disaster, because the mean age of the respondents was $>60$ years, it is considered that they do not know this service, so it is necessary to disseminate more information about such services and methods to the families.

\section{Factors affecting disaster prevention awareness among residents of mountainous areas}

From the results of the multiple regression analysis, "Number of years of residence" and "Experience participating in disaster prevention events" were extracted as factors affecting disaster prevention awareness.

In this study, those with a greater number of years of residence in City A had more experience participating in disaster prevention events and a higher degree of disaster prevention awareness. In addition, those who had more experience with a large-scale disaster and who had conversations about disaster prevention on a daily basis had a higher degree of disaster prevention awareness. Previous studies reported that the more years of residence, the higher the degree of disaster prevention 
Table 3 Factors affecting disaster prevention awareness $(\mathrm{n}=113)$

\begin{tabular}{|c|c|c|c|c|c|c|c|}
\hline & Variable & Category & Overall n (\%) & $\begin{array}{l}\text { Non- } \\
\text { standardization } \\
\text { factor } \\
\qquad \text { B }\end{array}$ & $\begin{array}{c}\text { Normalizing } \\
\text { constant } \\
\beta\end{array}$ & $p$ value & VIF \\
\hline \multirow{10}{*}{$\begin{array}{l}\text { Characteristics of } \\
\text { the participants }\end{array}$} & Constant & & & 62.882 & 0.000 & $0.000^{* *}$ & 0.000 \\
\hline & Number of years of residence & & & 0.134 & 0.255 & $0.011^{*}$ & 1.398 \\
\hline & \multirow[t]{2}{*}{ Sex } & Male & $54(47.8)$ & \multirow{2}{*}{1.062} & \multirow{2}{*}{0.046} & \multirow{2}{*}{0.611} & \multirow{2}{*}{1.184} \\
\hline & & Female & $59(52.2)$ & & & & \\
\hline & Occupation & Employed & $32(28.3)$ & \multirow{2}{*}{-3.453} & \multirow{2}{*}{-0.136} & \multirow{2}{*}{0.129} & \multirow{2}{*}{1.132} \\
\hline & & Unemployed & $81(71.7)$ & & & & \\
\hline & Household structure & Nuclear family & $61(54.0)$ & \multirow{2}{*}{1.941} & \multirow{2}{*}{0.084} & \multirow{2}{*}{0.328} & \multirow{2}{*}{1.064} \\
\hline & & Extended family & $52(46.0)$ & & & & \\
\hline & \multirow[t]{2}{*}{ Subjective health } & Healthy & $102(90.3)$ & \multirow{2}{*}{3.115} & \multirow{2}{*}{0.081} & \multirow{2}{*}{0.359} & \multirow{2}{*}{1.100} \\
\hline & & Unhealthy & $11(9.7)$ & & & & \\
\hline \multirow{8}{*}{$\begin{array}{l}\text { Factors related to } \\
\text { disaster prevention } \\
\text { awareness }\end{array}$} & \multirow{2}{*}{ Own disaster experiences } & Yes & $27(23.9)$ & \multirow{2}{*}{5.210} & \multirow{2}{*}{0.194} & \multirow{2}{*}{0.057} & \multirow{2}{*}{1.467} \\
\hline & & No & $86(76.1)$ & & & & \\
\hline & Disaster experiences among & Yes & $40(35.4)$ & \multirow{2}{*}{3.261} & \multirow{2}{*}{0.136} & \multirow{2}{*}{0.187} & \multirow{2}{*}{1.514} \\
\hline & people close to the participant & No & $73(64.6)$ & & & & \\
\hline & Conversations about disaster & Yes & $85(75.2)$ & \multirow{2}{*}{4.354} & \multirow{2}{*}{0.164} & \multirow{2}{*}{0.060} & \multirow{2}{*}{1.076} \\
\hline & prevention on a daily basis & No & $28(24.8)$ & & & & \\
\hline & Experience participating in & Yes & $77(68.1)$ & \multirow{2}{*}{4.877} & \multirow{2}{*}{0.198} & \multirow{2}{*}{$0.030^{*}$} & 1177 \\
\hline & disaster prevention events & No & $36(31.9)$ & & & & 1.171 \\
\hline
\end{tabular}

Multiple regression analysis: forced input method; contribution rate $\left(\mathrm{R}^{2}\right): 0.222$. VIF, variance inflation factor. ${ }^{*} p<0.05 ;{ }^{* *} p<0.01$.

awareness in the community (Russell, Goltz, \& Bourque, 1995). Hironaka et al. (2017) found that older adults participate in community activities more frequently than their younger counterparts, and that as they live longer, they participate in more community activities and increase their communication with residents, resulting in stronger connectedness with the community. Motoyoshi, Takao, and Ikeda (2008) reported that the intentions of local disaster prevention behaviors were higher with a greater awareness of the community, such as whether residents were committed to local autonomous activities or how much they interacted with people in their neighborhood. Hattori, Isowa, Hiramatsu, Kitagawa, and Tsujikawa (2020) found that close human interactions in the community facilitated disaster preparedness. Regarding the characteristics of mountainous areas in Japan, as represented by City A, there tend to be longstanding connections between residents because the aged population is high and the duration of residence is lengthy. Therefore, participation in not only local activities related to disaster prevention, such as disaster prevention events, but also local activities and discussions about disaster prevention on a daily basis, including what has been learned from a disaster experience, provide a concrete image of what can happen in a disaster, which can improve disaster prevention awareness.

\section{Relationship between disaster prevention aware- ness and preparation among residents of moun- tainous areas}

Those who were carrying out disaster preparedness had significantly higher total scores than those who were not for all items on the Disaster Prevention Awareness Scale except for "Be covered by earthquake insurance", which is difficult to address, even if disaster prevention awareness is high, because it represents an economic burden.

As the economic burden complicates disaster preparedness, it is also considered difficult for residents to utilize Earthquake insurance, irrespective of their awareness of the disaster. In addition, knowledge of earthquake insurance is low, probably because the most worrisome damage has been caused by tsunamis, which is not a concern of residents of mountainous areas.

\section{LIMITATIONS}

This study did have some limitations. First, it targeted the 
Table 4 Association between disaster prevention awareness and preparedness $(n=113)$

\begin{tabular}{|c|c|c|c|c|c|}
\hline Variable & Category & Overall n $(\%)$ & Mean & $\mathrm{SD}$ & $\begin{array}{l}t \text {-test; } p \\
\text { value }\end{array}$ \\
\hline \multirow{2}{*}{$\begin{array}{l}\text { Ensure that mobile radios, flashlights, and pharmaceuticals } \\
\text { can be accessed immediately }\end{array}$} & Yes & $76(67.3)$ & 84.0 & 12.0 & \multirow{2}{*}{$0.021^{*}$} \\
\hline & No & $37(32.7)$ & 78.7 & 9.5 & \\
\hline \multirow{2}{*}{ Identify evacuation sites and routes in the event of a disaster } & Yes & $74(65.5)$ & 84.7 & 11.4 & \multirow{2}{*}{$0.002^{* *}$} \\
\hline & No & $39(34.5)$ & 77.6 & 10.3 & \\
\hline \multirow{2}{*}{ Store food and drinking water } & Yes & $70(61.9)$ & 84.5 & 12.0 & \multirow{2}{*}{$0.009^{* *}$} \\
\hline & No & $43(38.1)$ & 78.7 & 9.7 & \\
\hline \multirow{2}{*}{ Prepare to collect valuable items } & Yes & $67(59.3)$ & 84.2 & 12.3 & \multirow{2}{*}{$0.032^{*}$} \\
\hline & No & $46(40.7)$ & 79.5 & 9.7 & \\
\hline \multirow{2}{*}{ Be covered by earthquake insurance } & Yes & $55(48.7)$ & 84.2 & 12.7 & \multirow{2}{*}{0.088} \\
\hline & No & $58(51.3)$ & 80.5 & 10.0 & \\
\hline \multirow{2}{*}{ Actively participate in disaster prevention training } & Yes & $52(46.0)$ & 87.5 & 12.4 & \multirow{2}{*}{$0.000^{* *}$} \\
\hline & No & $61(54.0)$ & 77.8 & 8.4 & \\
\hline \multirow{2}{*}{$\begin{array}{l}\text { Secure furniture and appliances to prevent them from falling } \\
\text { and moving }\end{array}$} & Yes & $46(40.7)$ & 85.7 & 14.1 & \multirow{2}{*}{$0.017^{*}$} \\
\hline & No & $67(59.3)$ & 80.0 & 8.7 & \\
\hline \multirow{2}{*}{$\begin{array}{l}\text { Talk to neighbors and friends about helping each other } \\
\text { in the case of a disaster }\end{array}$} & Yes & $43(38.1)$ & 88.5 & 12.3 & \multirow{2}{*}{$0.000^{* *}$} \\
\hline & No & $70(61.9)$ & 78.4 & 9.1 & \\
\hline \multirow{2}{*}{$\begin{array}{l}\text { Determine how to check the safety of family members } \\
\text { during a disaster }\end{array}$} & Yes & $44(38.9)$ & 90.1 & 10.9 & \multirow{2}{*}{$0.000^{* *}$} \\
\hline & No & $69(61.1)$ & 77.3 & 8.8 & \\
\hline \multirow{2}{*}{ Prepare clothing and blankets for emergencies } & Yes & $29(25.7)$ & 91.6 & 11.2 & \multirow{2}{*}{$0.000^{* *}$} \\
\hline & No & $84(74.3)$ & 79.1 & 9.8 & \\
\hline
\end{tabular}

SD, standard deviation.

${ }^{*} p<0.05 ;{ }^{* *} p<0.01$.

inhabitants of only one city, so caution is needed when generalizing the results to all mountainous areas. Second, the survey was conducted with participants who had a residential health examination, who likely have greater health awareness than the general population; this may have led to a selection bias. In addition, the mean age of the respondents was $>60$ years, and the limited number of responses from younger people and adults may have influenced variables such as "Number of years of residence" and "Experience participating in disaster prevention events".

\section{CONCLUSION}

In this study, the implementation rate of disaster prevention awareness and preparedness among residents of a mountainous areas in Japan was higher than that from a national survey. However, the implementation rate of disaster preparedness was only $\sim 30 \%$ for some items. From the results of the multiple regression analysis, "Number of years of residence" and "Experience participating in disaster prevention events" were extracted as factors affecting disaster prevention awareness. In relation to disaster prevention awareness and prepared- ness, associations were found for all items except "Be covered by earthquake insurance".

These results suggest that disaster prevention awareness and preparedness implementation rates need to be improved among residents of mountainous areas in Japan. Therefore, we believe that it is important to encourage residents not only to mention local activities related to disaster prevention such as disaster prevention events, but also to participate actively, and to increase opportunities to think about disaster prevention so that they can have a concrete image of what can happen in a disaster.

\section{DISCLOSURE}

The authors have no conflicts to disclose.

\section{ACKNOWLEDGMENTS}

This study was carried out with the cooperation of the City A Health Center. This work did not receive any grants from funding agencies in the public, commercial, or not-for-profit sectors. We would like to express our deepest gratitude to the staff of the A City Health Center 
and the residents who completed the survey.

\section{AUTHORS' CONTRIBUTIONS}

All authors contributed to the conception and design of this study; HK, AS, MT performed the statistical analysis and drafted the manuscript; SI critically reviewed the manuscript and supervised the whole study process. All authors read and approved the final manuscript.

\section{REFERENCES}

Arias, J. P., Bronfman, N. C., Cisternas, P. C., \& Repetto, P. B. (2017). Hazard proximity and risk perception of tsunamis in coastal cities: are people able to identify their risk? PLOS ONE, $12(10), \mathrm{e} 0186455$.

Cabinet Office (Japan). (2002). Public opinion survey on disaster reduction (September 2002 survey). (in Japanese). [Cited 19 May 2020.] Available from URL: https://survey.gov-online. go.jp/h14/bousai-h14/index.html

Cabinet Office (Japan). (2010). White paper on disaster management 2010 summary. (in Japanese). [Cited 19 May 2020.] Available from URL: http://www.bousai.go.jp/kaigirep/ hakusho/h22/bousai2010/html/zu/zu001.htm

Cabinet Office (Japan). (2016). Survey results on disaster prevention consciousness and activities in daily life. (in Japanese). [Cited 19 May 2020.] Available from URL: http:// www.bousai.go.jp/kohou/oshirase/pdf/20160531_02kisya.pdf

Cabinet Office (Japan). (2017). Public opinion survey on disaster reduction (November 2017 survey). (in Japanese). [Cited 19 May 2020.] Available from URL: https://survey.gov-online. go.jp/h29/h29-bousai/index.html

Cabinet Office (Japan). (2019a). White paper on disaster management 2019 summary. (in Japanese). [Cited 19 May 2020.] Available from URL: http://www.bousai.go.jp/kaigirep/ hakusho/h31/honbun/0b_1s_00_00.html

Cabinet Office (Japan). (2019b). Basic plan for disaster prevention. (in Japanese). [Cited 19 May 2020.] Available from URL: http://www.bousai.go.jp/taisaku/keikaku/pdf/kihon_basic_ plan190531.pdf

Fujimura, K., Ishii, K., Sakaguchi, M., Murakawa, Y., \& Akihara, S. (2013). Self-care support for survival citizens: relationship between knowledge, attitude, and practice of disaster preparedness. Osaka City University Journal of Nursing, 9, 21-30. (in Japanese)

Gisela, W., Ortwin, R., Chloe, B., \& Christian, K. (2013). The risk perception paradox - implications for governance and communication of natural hazards. Risk Analysis, 33(6), 1049-1065.

Hattori, Y., Isowa, T., Hiramatsu, M., Kitagawa, A., \& Tsujikawa, M. (2020). Disaster preparedness of persons requiring special care ages 75 years and older living in areas at high risk of earthquake disasters: a cross-sectional study from the Pacific Coast region of Western Japan. Disaster Medicine and Public
Health Preparedness, 19, 1-9.

Hironaka, A., Tanaka, K., Yamane, C., Hitomi, E., Nakamura, B., Yoshimura, K, et al. (2017). A study of factors associated with awareness of natural disasters and actions for disaster prevention among residents in Yamaguchi Prefecture. Yamaguchi Prefectural University Academic Information, 10, 99-109. (in Japanese)

Ishihara, R., \& Matsumura, N. (2012). The study on the structure of resident consciousness according to disaster reduction in harmony with our daily life in the coastal regions -Tokushima Prefecture Anan City as a case-. Journal of City Planning Institute of Japan, 47(3), 1069-1074. (in Japanese)

Koshimura, S., \& Shuto, N. (2015). Response to the 2011 Great East Japan Earthquake and Tsunami disaster. Philosophical Transactions of the Royal Society A: Mathematical, Physical and Engineering Sciences, 373, 20140373.

Ministry of Land, Infrastructure and Transport (MLIT) (Japan). (2011). White paper on land, infrastructure, transport and tourism 2011, section 2 preparing for the next disaster. (in Japanese). [Cited 19 May 2020.] Available from URL: https:// www.mlit.go.jp/hakusyo/mlit/h22/hakusho/h23/index.html

Ministry of Land, Infrastructure and Transport (MLIT) (Japan). (2019). Heavy rain in July 2018: response to road disasters in the Shikoku region. (in Japanese). [Cited 19 May 2020.] Available from URL: https://www.skr.mlit.go.jp/road/h30_ 7gatsugou/h30_7gatsugou.html

Motoyoshi, T., Takao, K., \& Ikeda, S. (2008). Determinants of household- and community-based disaster preparedness. Social Psychology Research, 23(3), 209-220. (in Japanese)

National Research Institute for Earth Science and Disaster Resilience (NIED) (Japan). (2017). Research project on disaster countermeasures based on the utilization of natural disaster information. (in Japanese). [Cited 19 May 2020.] Available from URL: https://risk.ecom-plat.jp/index.php?gid= 11139

Ozeki, M., Shimazaki, K., \& Yi, T. (2017). Exploring elements of disaster prevention consciousness: based on interviews with anti-disaster professionals. Journal of Disaster Research, 12(3), 631-638.

Reininger, B. M., Raja, S. A., Carrasco, A. S., Chen, Z., Adams, B., McCormick, J., et al. (2013). Intention to comply with mandatory hurricane evacuation orders among persons living along a coastal area. Disaster Medicine and Public Health Preparedness, 7, 46-54.

Russell, L., Goltz, J. D., \& Bourque, L. B. (1995). Preparedness and hazard mitigation actions before and after two earthquakes. Environment and Behavior, 27, 744-770.

Shimazaki, K., \& Ozeki, M. (2017). Development of a new disasterprevention consciousness scale (1). The 81st Annual Meeting of the Japanese Psychological Association, 69. Kurume: The Japanese Psychological Association. (in Japanese)

Takahashi, K., \& Masaki, M. (2012). How the Great East Japan Earthquake changed the Japanese: from a public opinion survey on disaster prevention, energy and basic sense of values. The NHK Monthly Report on Broadcast Research, 62(6), 34-55. (in Japanese) 